\title{
The Chinese learner in the New Zealand university environment
}

\section{CAROLYN TAit}

\begin{abstract}
There are increasing numbers of Chinese students in New Zealand tertiary institutions. These students are challenged to adjust to new learning environments but, at the same time, staff are challenged to adjust to their teaching to include these students. The Student Approaches to Learning ( $S A L$ ) theory provides a means to consider literature that is relevant in understanding the motives and strategies that these students bring to New Zealand and the process of change in a new learning environment. This knowledge may allow tertiary educators to consider their role in facilitating desirable approaches to learning in diverse student groups.
\end{abstract}

\section{Introduction}

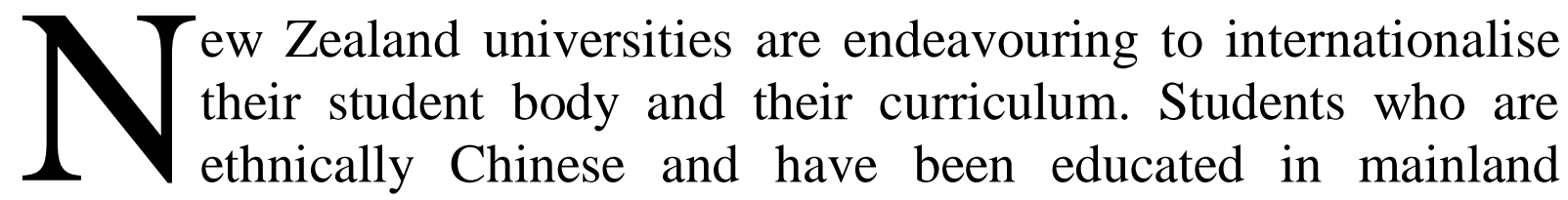
China, Hong Kong or Taiwan are becoming increasingly prevalent among the culturally and linguistically diverse population of tertiary learners. In 2011, of the 18,918 international students enrolled in universities in New Zealand, 6,199 students were from China (Ministry of Education, 2012). The presence of these students challenges staff to consider how to teach these linguistically and culturally diverse students effectively. While universities in New Zealand set minimum language requirements and academic entry standards, academic achievement in their home country and proficiency in English may be just two of the many complex factors that contribute to successful learning in a new educational environment. These students may have experienced very different 
learning trajectories in their lives compared to students who have been educated in Western contexts. Not only are students going through an adjustment process, educators are also required to adjust to working with very diverse learning communities.

While there is a growing body of literature which informs the teaching and learning of Chinese students, whether they are in China, Hong Kong or Taiwan or studying overseas, there is a need to consider how particular elements of this literature inform teaching and learning for Chinese students in the specific context of New Zealand tertiary education. This thematic review of the literature selectively focuses on those aspects that may inform the teaching of Chinese international students in university courses in New Zealand. Using the Student Approaches to Learning theory (SAL) (Biggs, 2003), this review argues that Chinese learners studying abroad are influenced by the teaching context as well as what they bring from their home environment.

\section{Student approaches to learning theory}

SAL theory has been described as "a meta-theory for conceptualising learning and teaching” (Biggs, Kember, \& Leung, 2001, p. 134). The notion of different types of approaches to learning originated in the SAL research (Marton \& Säljö, 1976a, 1976b). Each approach to learning is characterised by motives and strategies. A surface approach to learning is seen as resulting from a desire to do no more work than was needed to pass. In this approach, students target only the essentials of a course and use rote memorisation to remember facts and details rather than understanding important concepts. In contrast, a deep approach is associated with an intrinsic interest in what was being learned and comes from a desire to develop competence in the subject that was being studied. The deep approach to learning is aimed at developing complex interrelationships with previous knowledge which involves reading widely and seeking understanding (Biggs, 2003; Kember, Biggs, \& Leung, 2004).

To gain insight into how this theory might aid teachers in New Zealand to understand the motives and strategies of the Chinese learners they teach, first it is necessary to consider Chinese learners 
studying in New Zealand, and the cultural influences on their perceptions of education, strategies, and motivation. Intersecting with this is the literature pertaining to the teaching and learning of Chinese students in Western contexts. By considering the complexity of factors that influence the motives and strategies of Chinese students studying in New Zealand, educators may be encouraged to move beyond the stereotypes that have been created of Chinese learners as having a surface approach to learning (Volet, 1999).

\section{Who is the Chinese learner?}

While the concept 'the Chinese learner' is not static or necessarily well defined, an empirically-based understanding, rather than one based on stereotypes constructed by others, can be useful. Chinese students are identified not just by their ethnicity, place of birth and language, but also by their participation in cultural communities. Cultural communities are defined as "a coordinated group of people with some traditions and understandings in common, extending over several generations, with varied roles and practices and continual change among participants as well as transformation in the community's practices” (Gutierrez \& Rogoff, 2003, p. 21). This suggests dynamic processes and identities, rather than static individual traits (Doherty \& Singh, 2005).

\section{Western academics' construction of "the Chinese learner"}

Stereotypes of Chinese learners created in the '80s saw these students as rote learners, excessively respectful of the teacher, quiet in class, and overly concerned with assessment (Ballard \& Clanchy, 1984; Samuelowicz, 1987). These learners were seen to rely on rote learning that is associated with a surface approach to learning. Indeed, they were perceived as unable to engage in the critical thinking required by Western institutions until they let go of their former learning styles. Saravanamuthu, and Tinker (2008) argue that these stereotypes continue in western universities.

Perceptions of lecturers in five tertiary institutions in Hong Kong showed similar views (Jackson, 2005). Lecturers thought that students did not actively participate in class, had weak problem-solving skills, 
and took a surface approach to learning. They complained that students memorised textbooks in preparation for assessments. As a result of these perceived attributes, lecturers felt forced to use less demanding forms of assessment that required fewer analytical skills. Devos (2003), in analysing the discourse around international students, concludes that a debate of academic standards casts Australian academics as 'victim' and that international students are constructed as 'other'. These studies indicate that the stereotypes of Chinese students continue to exist.

In Volet's (1999) study, the characteristics attributed to learners from Confucian Heritage Culture (CHC) backgrounds were examined for congruence with those characteristics believed to be appropriate in a western university setting. High levels of motivation, attribution of success to effort rather than ability, deep approaches to learning, and working in informal study groups were seen as appropriate for studying in Australian universities. Cue-seeking to identify assessment demands and memorisation of study materials are areas where there is limited consensus about whether transfer was appropriate. Chinese students' perceptions of the role of teachers were not considered to transfer well. Asian students expect teachers to provide help outside class, rather than spending time answering questions during classes. Strategies seen as unacceptable in Australian universities but considered acceptable in their home country were labelled as inappropriate transfer. These strategies included reporting verbatim and copying relevant extracts in assignments without acknowledgment. Volet (1999) pointed out that those characteristics that appeared to transfer well were related to students' belief systems about learning. The aspects of learning that did not transfer so well are related to how the students responded to the learning environment either in their home or host country. An example was rote memorisation which may have been the students' response to a heavy assessment load, or a strategy to enable students to overcome the difficulties of learning in a second language.

While it is important to be aware that this labelling of Chinese students is a way in which "we put ourselves in the powerful position of rhetorically constructing their identities, [it is] a potentially 
hazardous enterprise” (Spack, 1997, p. 765). Educators and researchers should also recognise international students as a "new diaspora" (Rizvi, 2000, p. 223) who with their subsequent intercultural identity will have considerable global influence. The discourse of cultural identity is used to contest the images of Asian students as 'other' who are passive rote learners. Rather, they saw Asian international students as having fluid identities that developed as they made "biographical investments for liquid times” (Doherty \& Singh, 2005, p. 1). Morris (2005) challenged educators not to marginalise these students according to their differences. This notion of change suggests that Chinese students studying abroad may approach learning differently in new environments. This places responsibility on educators in New Zealand to use teaching and assessment practices to generate approaches to learning that they would see as desirable.

\section{Chinese learners in New Zealand}

Chinese learners in New Zealand are themselves diverse. One limitation of the term 'the Chinese learner' is that it can be derived from a geographic region which, in itself, includes diverse cultures (Clarke \& Gieve, 2006). Even within mainland China there are 55 national minority peoples. By labelling Chinese students, the literature could create an image of Chinese learners that is homogeneous and static.

When considering Chinese students studying in New Zealand, a recognition that the characteristics of this group of students has changed over time enables educators to understand their learners. Not only has the educational context within China changed, but so too has the kind of student going abroad to study (Jin \& Cortazzi, 2006). Mainland China is now offering many more places to students who wish to go to university within their home country (Bai, 2006). Previously, western universities were ranked above Chinese institutions (Chan, 1999), but now some Chinese universities are ranked more highly. Because of the increased number of places available in Chinese universities, top students are now choosing highly ranked Chinese universities over lower ranked overseas universities. Twenty years ago, Chinese students were likely to be 
funded by their government to study abroad. Now, students who do go abroad to study are likely to be funded by their family. In addition, these students are likely to have experienced educational reforms in teaching English in China before they depart for overseas countries (Jin \& Cortazzi, 2006). Shi (2006) described the social context of learning in China as a "moving target" (p. 139) because of the educational changes that are continuously being implemented.

The New Zealand university environment has also changed for Chinese learners. For example, since the late 1990s the numbers of Chinese students in New Zealand has grown (Bai, 2008). The type and duration of Chinese students' experiences abroad have also changed because of New Zealand government regulations which allow students to come to New Zealand at an earlier age. Since 1999, Chinese international students have been able to enrol in New Zealand secondary schools. These students have spent more time studying in New Zealand than previous students who entered university directly from their home regions. Universities have developed policies for internationalisation, and a body of research on Chinese learners in western education and specific to New Zealand education has been generated (Ho, Li, Cooper, \& Holmes, 2007). This research has the potential to influence Chinese students' experiences at an institutional level and a classroom level.

Students coming to New Zealand are influenced by changing environments both in their home regions and in New Zealand. In addition, the student population has changed, and the process of studying abroad itself influences the students. This suggests a complex interaction among home and host environments and the learners necessitating continual re-examination of any stereotypes that exist.

\section{Cultural influences on approaches to learning}

The term 'Chinese students' has been used to characterise a subset of a bigger group of 'Asian learners' (Wong, 2004). There are two common frameworks that are used to characterise Asian students. One distinguishes them as coming from collectivist cultures (Hofstede, 1986; Ho, Holmes, \& Cooper, 2004). Using this framework, Chinese learners would be likely to view education as a way of gaining higher social status in a society that values qualifications. They would uphold 
tradition, seek harmony and endeavour to preserve face by behaviours such as not speaking in class unless called upon (Ho et al., 2004). The other framework characterises students as belonging to CHC (Chan, 1999; Lee, 1996). In this tradition, learners are expected to work hard, show respect to teachers, revere knowledge, and strive to become good people. These two influences on Chinese students are interconnected and overlapping and may contribute to the beliefs that the students bring with them to New Zealand universities.

\section{Cultural influences on study strategies}

Memorisation and surface approaches to learning have been associated with Chinese learners in western universities (Volet, 1999). However, memorisation and understanding are not a dichotomy for Chinese students. In their qualitative study of 20 mainland Chinese teacher educators, Marton, Dall'Alba, and Tse (1996) identified different forms of memorisation, distinguishing between mechanical memorisation and memorisation with understanding. They further divided memorisation with understanding into two new parts, memorising what has been understood and understanding through memorisation. These authors argued that forms of repetition, while appearing to be rote learning, could actually deepen understanding for Chinese learners by focusing on different aspects of the knowledge.

Sachs and Chan (2003) followed up on this quantitatively and qualitatively. Their quantitative findings, using ranking of conceptions of learning with dual scaling analysis, indicated that Chinese learners see memorisation as distinct from understanding, but the interviews that followed revealed that memorisation was integral to understanding. They argued that the connections between memorisation and understanding may develop in specific contexts such as in response to assessment.

It is this ability to use memorisation with understanding that may allow for success in examinations that require these skills in a western context (Tait, 2010; Wang \& Byram, 2011). The demands of the assessment may influence conceptions of learning for Chinese learners (Au \& Entwistle, 1999). Memorisation as a study approach in preparation for assessment seemed to be closely connected with 
understanding. This nature of memorisation may change over time and in different contexts for Chinese students (Marton, Wen, \& Wong, 2005).

The idea that CHC traditions produce surface learners is open to debate (Biggs, 1996; Lee, 1996). Early Confucian education encompassed understanding developed through a Socratic style. Jin and Cortazzi (2006) see the CHC construction of the Chinese student as a representation of positive, desirable personal traits that have been developed within the educational contexts of learning in the students' home countries. It is their opinion that the long process of learning Chinese characters, which requires modelling, repetition and active memorisation, influences how Chinese children see the learning process. This approach to teaching is reinforced by the way English is taught at school. Jin and Cortazzi (2006) provide a model of how student learning is conceived in CHC societies. At the centre of this model is the continuous effort that is needed to study, inquire, think critically, and practise. This continuous effort is based on the premise that "If you make enough effort, you can grind the iron pillar into a needle" (Chinese proverb cited in Jin \& Cortazzi, 2006, p. 13). Chinese students are likely to attribute success to effort rather than ability which sheds light on how the process of repetition and memorisation is used with the intention of developing understanding (Dahlin \& Watkins, 2000).

These cultural traditions of active memorisation and effort attribution may influence Chinese students in their study overseas. Surface and deep approaches to learning have been investigated in studies of Asian students studying abroad in the discipline of business and commerce (Cooper, 2004; Donald \& Jackling, 2007; Holmes, 2004; Ramburuth \& McCormick, 2001). Chinese students reported a higher deep approach and a higher surface approach than domestic students in an Australian study of accounting students in Australian universities (Cooper, 2004). Donald and Jackling, (2007) conclude from their comparison of Australian and Chinese students that the latter are more likely to have a deep approach to learning. Holmes (2004) finds that the overlap between deep and surface learning is not clear for Chinese students in New Zealand. These results illustrate the complex 
contribution of memorisation in bringing about understanding when Chinese students study abroad, and suggests that stereotypes of Chinese students as being over dependent on surface learning may be a misleading simplification for teaching staff.

These studies indicate that Chinese students in New Zealand universities will use memorisation but not necessarily only as a surface approach to learning. They may use memorisation in response to assessment and as part of the process of developing deep understanding.

\section{Cultural influences on motivation}

Much has been written on the competitive nature of Asian learners and their emphasis on success in examinations (Chan, 1999; Volet, 1999; Yan \& Chow, 2002). In a survey of over 50015 to 17 year olds from three different regions of the People's Republic of China, Watkins (2007) concluded that Chinese students often saw a competitive environment as a stimulus for learning and selfimprovement. However, there are conflicting views about the basis of motivation for success.

One view of motivation is founded on the collectivist nature of Chinese culture and its focus on interdependence (Hofstede, 1986). In this culture, significant others are not so much seen as a standard against which to compare oneself and one's own achievements, but as part of a context to which a person is intimately connected and linked to family pride (Kumar \& Maehr, 2007). Salili (1996), in her review of the literature, also found that Chinese students had a collectivist approach to motivation. However, not all research corroborates the concept of interdependence for Chinese learners.

More recently, Shi (2006) gathered information from 400 middle school students in China and found that the new generation of students is more motivated by self than family to learn English. This may signal a shift in values in these students who are the second generation of one child families in mainland China. On the other hand, Li (2006) attributes the increase in individual over social goals among mainland Chinese adolescents in China to the Confucian virtue which emphasises the development of moral self-perfection as an individual 
path. In her study, the findings showed that Chinese students were more aware of mastery than performance goals and expressed more personal agency than social agency. While there are conflicting views about the sources of the motivation that Chinese students bring to their study, western educators perceive the Chinese learners' high levels of motivation as a desirable quality (Volet, 1999).

Another source of motivation, closely related to interdependence, is founded on potential career prospects. Chinese students want their courses to be relevant to future careers. In a study based on interviews of 36 university students in Hong Kong, Kember, Ho, and Hong (2008) identify 'relevance' as an important motivating factor for Chinese students choosing courses that lead to professional careers. The data indicated that students selected courses on the basis of career prospects despite having little knowledge of the programme or the career that they had selected. Students found theory without practical applications demotivating. It was the application of theory to practice and establishing its relevance to current issues that promoted motivation. In China, students (or their parents) often selected disciplines linked to future careers. The concept of generic skills and learning for its own sake is seen as something new and may be acquired while studying in a western university setting (Wang \& Byram, 2011). This change in the source of motivation supports the notion of the changes that may occur in new learning environments.

Extrinsic motivation for Chinese students studying in New Zealand may relate to what Bai (2008, p. 226) labels "the perceived gold content" of their degree. From her survey of 457 Chinese international students studying in New Zealand, she attempts to resolve the apparent anomaly that Chinese students may be more dissatisfied with their education in New Zealand than other international students and yet most are likely to want to stay in New Zealand. By examining the results of her survey in light of the changes that have occurred in mainland China, she shows that the value of a New Zealand degree in China as a ticket for getting a job has fallen. The changing political and social situation in China means there are now more places available for students in Chinese universities and at the same time there is considerable graduate unemployment. The best Chinese 
universities are now seen as elite. At the same time students going abroad may be of lower ability than the government sponsored students of the 1980s and early 90s. Since graduates from New Zealand universities are not seen as internationally competitive, some Chinese students aspire to getting a job in New Zealand.

\section{Learning in new contexts}

Adjustment to different educational contexts

Chinese students face considerable adjustments when undertaking tertiary education in a western university. Biggs and Watkins (2001) describe a pedagogical flow which arises from the culture and values of a country. In tertiary institutions, "the onus [is] on these Chinese students to reconstruct and renegotiate their primary culture learning and communication styles to accommodate another way" (Holmes, 2004, p. 301). This was also evident in an investigation of the impact of international students on host institutions in New Zealand (Ward, 2001). Turner (2006) reflected on the interactions of a group of Chinese graduate students in a British university and concluded that it was "the culturally implicit nature of UK academic conventions" (p. 27) that meant the students did not change their approaches over the course of a year of study. This lack of explicit knowledge of academic conventions is also a challenge for Chinese tertiary students studying in New Zealand (Campbell \& Li, 2008). The adjustment to a different academic environment has been described as a "learning shock” for Chinese students (Gu \& Schweisfurth, 2006, p. 82).

Language was identified as a barrier to learning for Asian students in universities where English is the language of instruction (Heggins \& Jackson, 2003; Holmes, 2004, 2005; Lee, 2007). Holmes (2004), in her longitudinal study of 13 Chinese students in a New Zealand university, pointed out the difficulties students experienced in listening to, and understanding, the language of lectures, as well as managing the volume and quality of academic reading and writing expected in university courses. Language, rather than culture, is identified as the reason why East Asian learners are reluctant to participate in western university classes (Briguglio \& Smith, 2012; Heggins \& Jackson, 2003; Lee, 2007). This suggests that lecturers 
need expertise in teaching and assessing students whose home languages are not English.

At the same time as they are adjusting to a new educational environment, Chinese students experience the psychological and social impact of culture shock. There is evidence that students face financial pressures, find the process of language learning more difficult than anticipated, perceive prejudice, feel lonely, and do not achieve the level of interaction with host nationals that they desired (Robertson, Line, Jones, \& Thomas, 2000; Spencer-Oatey \& Xiong, 2006; Zhang \& Brunton, 2007). Low social self-efficacy for both domestic and international students contributed towards a lack of interaction between these two groups. This limited interaction was likely to be confined to the classroom, rather than a social setting (Brown \& Daly, 2005).

Highly skilled educators and administrators are needed to support international students so that they can succeed in a western university setting. Simpson and Tan (2009) used focus groups in a New Zealand tertiary institution to find out the Chinese students' most important criteria for evaluating their educational experience. The students prioritised interpersonal aspects such as administrative and academic support over campus environment and curriculum quality. They valued experienced teaching staff who were good communicators and made themselves available to students. Skyrme (2007) concluded that universities in New Zealand have a responsibility to provide greater levels of teacher guidance during the early stages of study for Chinese students. Cross-cultural communication skills can be informed by knowledge of the way Chinese students perceive their study in New Zealand. Specific skills are required to teach in an intercultural setting (Teekens, 2003). The discourses that underlie the teaching processes in a western university are the accepted and often unchallenged norm (Turner, 2006). At the same time, they may not be made explicit for international students. This disadvantages these students and signifies the need for universities to re-examine their practices (Campbell \& Li, 2008). 


\section{Dialogic versus didactic approaches to teaching}

There is often an assumption that Chinese students will have come from backgrounds with a didactic approach to teaching and that they are adjusting to a more student-centred dialogic approach to teaching. Some New Zealand findings support this (Holmes, 2004, 2005; Li, Baker, \& Marshall, 2002) and may attribute it to Confucian attitudes towards hierarchy which discourage participation in classroom discussion and critical thinking. Chinese students may see questioning during class as a challenge to the teacher's authority and contrary to the need to preserve harmony and face (Holmes, 2005).

However, course design and pedagogy play a role in fostering critical thinking and participation. Chinese international students showed a similar level of critical thinking to other students when engaged in a task in an introductory economics class in an Australian university (Jones, 2005). This was despite the fact that they were not working in their first language and they had not experienced similar tasks in their previous education. Jones concluded that the context, including the teaching and assessment, was very important in influencing students' approaches to learning. Chinese students may use skills such as metacognition developed in their home country and build new conceptions of learning that include a valuing of critical thinking in a different education environment (Wang \& Byram, 2011).

Further literature casts doubt on some of the characteristics of Chinese learners that are attributed to Confucian traditions such as reticence to speak in class unless called upon (Liu \& Littlewood, 1997; Shi, 2006). In a large-scale study of university students in Hong Kong, Liu and Littlewood (1997) found that students wanted opportunities to speak in class. These authors attributed the students' reticence in class to their learning experiences at high school where they were required to keep quiet and listen, which contributed to their lack of confidence in using oral English. Shi (2006) found that Chinese middle school students wanted to ask their teachers questions and believed that their teachers would be willing to answer them.

The stereotype of Chinese learners who prefer didactic approaches may be based on a response to the teaching and learning conditions rather than a cultural preference. McKay and Kember (1997) 
challenge the reported preferences of Chinese students for a didactic approach to teaching involving rote memorisation of facts. In their study they compared two intakes in a Hong Kong diploma course before and after the course had been revised in line with principles for engaging students in deep learning. Students preferred the studentcentred learning environment and had a positive approach to deep learning. Problem-based learning, group projects, and peer teaching were regarded very positively by Hong Kong students in a large-scale teaching innovation study (Kember, 2000). Students may prefer student-centred approaches to learning rather than the more didactic approaches experienced in their previous education (Wong, 2004). Even though dialogic approaches may be the preference for some Chinese students, those in New Zealand universities report that it was difficult to adjust to the change in approaches from their previous education (Holmes, 2004). To teach students in a culturally responsive way, university staff may need to know what students bring from previous learning environments in their home regions. This may allow both teachers and students to adjust to a new learning environment which includes Chinese students.

\section{Conclusion and implications}

Studies conducted in New Zealand and Australia and other pertinent literature that has been reviewed here show the importance of the educational environment on motivation and engagement of Chinese learners. An awareness of these students' culture and how culture may influence learning and teaching may assist in equipping lecturers to teach these students more effectively within specific disciplines.

Both New Zealand tertiary educators and Chinese students are challenged to adjust to a new environment for learning as these students become part of the population in New Zealand tertiary institutions. By considering the literature that pertains to Chinese students' motives and strategies, it is possible to highlight the responsibility of educators in creating learning environments that foster desirable approaches to learning. 


\section{References}

Au, C., \& Entwistle, N. (1999, August). Memorising and understanding in approaches to studying: Cultural variant or response to assessment demands. Paper presented at the European Association for Research on Learning and Instruction Conference, Gothenburg. Retrieved April 14, 2009, from hppt://www.leeds.ac.uk/educol/documents/00001729.htm =

Bai, L. (2006). Graduate unemployment: Dilemmas and challenges in China's move to mass higher education. The China Quarterly, 185, 128-144.

Bai, L. (2008). The influence of Chinese perceptions of modernisation on the value of education: A case study of Chinese students in New Zealand. China: An International Journal, 6(2), 208-236.

Ballard, B., \& Clanchy, J. (1984). Study abroad: A manual for Asian students. Kuala Lumpur: Longman.

Biggs, J. (1996). Western misconceptions of Confucian heritage learning culture. In D. Watkins \& J. Biggs (Eds.), The Chinese learner: Cultural, psychological and contextual influences (pp. 45-68). Melbourne: Australian Council for Educational Research.

Biggs, J. (2003). Teaching for quality learning at university. Buckingham: The Society for Research into Higher Education and Open University Press.

Biggs, J., Kember, D., \& Leung, D. (2001). The revised two-factor Study Process Questionnaire: R-SPQ-2f. British Journal of Educational Psychology, 71, 133-149.

Briguglio, C., \& Smith, R. (2012). Perceptions of Chinese students in an Australian university: Are we meeting their needs? Asia Pacific Journal of Education, 32(1), 17-33.

Brown, J. C., \& Daly, A. J. (2005). Intercultural contact and competencies of tertiary students. New Zealand Journal of Educational Studies, 40(1), 85-100.

Campbell, J., \& Li, M. (2008). Asian students' voices: An empirical study of Asian students' learning experiences at a New Zealand university. Journal of Studies in International Education, 12, 375-396.

Chan, S. (1999). The Chinese learner: A question of style. Education \& Training, 41(6/7), 294-304.

Clarke, R., \& Gieve, S. (2006). On the discursive construction of "the Chinese learner”. Language, Culture and Curriculum, 19(1), 54-73.

Cooper, B. (2004). The enigma of the Chinese learner. Accounting Education: An International Journal, 13(3), 289-310.

Dahlin, B., \& Watkins, D. (2000). The role of repetition in the processes of memorising and understanding: A comparison of the views of German and Chinese secondary school students in Hong Kong. British Journal of Educational Psychology, 70, 64-84. 
Devos, A. (2003). Academic standards, internationalisation and discursive construction of "the international student". Higher Education Research and Development, 22(2), 155-166.

Doherty, C., \& Singh, P. (2005). International student subjectivities. Paper presented at AARE Education Research Conference, Sydney.

Donald, J., \& Jackling, B. (2007). Approaches to learning accounting: A cross cultural study. Asian Review of Accounting, 15(2), 100-121.

Gu, Q., \& Schweisfurth, M. (2006). Who adapts? Beyond cultural models of 'the Chinese learner'. Language, Culture and Curriculum, 19(1), 74-89.

Gutierrez, K., \& Rogoff, B. (2003). Cultural ways of learning: Individual traits or repertoires of practice. Educational Researcher, 32(5), 19-25.

Heggins, W., \& Jackson, J. (2003). Understanding the collegiate experience for Asian international students at a midwestern research university. College Student Journal, 37(3), 379-393.

Ho, E., Holmes, P., \& Cooper, J. (2004). Review and evaluation of international literature on managing cultural diversity in the classroom. Wellington: Ministry of Education.

Ho, E., Li, W., Cooper, J., \& Holmes, P. (2007). The experiences of Chinese International students in New Zealand. Report for Education New Zealand. Hamilton: University of Waikato

Hofstede, G. (1986). Cultural differences in teaching and learning. International Journal of Intercultural Relations, 10(3), 301-320.

Holmes, P. (2004). Negotiating difference in learning and intercultural communication. Business Communication Quarterly, 67(3), 294-307.

Holmes, P. (2005). Ethnic Chinese students' communication with cultural others in a New Zealand university. Communication Education, 54(4) 289-311.

Jackson, J. (2005). An inter-university, cross-disciplinary analysis of business education: Perceptions of business education in Hong Kong. English for Specific Purposes, 24(3), 293-306.

Jin, L., \& Cortazzi, M. (2006). Changing practices in Chinese cultures of learning. Language, Culture and Curriculum, 19(1), 5-20.

Jones, A. (2005). Culture and context: Critical thinking and student learning in introductory economics. Studies in Higher Education, 30(3), 339-359.

Kember, D. (2000). Misconceptions about the learning approaches, motivation and study practices of Asian students. Higher Education, 40, 99-121.

Kember, D., Ho, A., \& Hong, C. (2008). The importance of establishing relevance in motivating student learning. Active Learning in Higher Education, 9, 240-263.

Kumar, R., \& Maehr, M. (2007). Cultural interpretations of achievement orientations. In F. Salili \& R. Hoosain (Eds.), Culture, motivation and learning: A multicultural perspective (pp. 43-66). Charlotte, NC: Information Age. 
Lee, E. (2007). Linguistic and cultural factors in East Asian students' oral participation in U.S. university classrooms. International Education, 36(2), 27-106.

Lee, W. (1996). The cultural context for Chinese learners: Conceptions of learning in a Confucian tradition. In D. Watkins \& J. Biggs (Eds.), The Chinese learner: Cultural, psychological and contextual influences (pp. 25-42). Melbourne: Australian Council for Educational Research.

Li, J. (2006). Self in learning: Chinese adolescents' goals and sense of agency. Child Development, 77(2), 482-501.

Li, M., Baker, T., \& Marshall, K. (2002). Mismatched expectations: A case study of Asian students in New Zealand. New Zealand Journal of Applied Business Research, 1, 137-156.

Liu, N., \& Littlewood, W. (1997). Why do many students appear reluctant to participate in classroom learning discourse? System, 25(3), 371-384.

Marton, F., \& Säljö, R. (1976a). On qualitative differences in learning - I: Outcome and process. British Journal of Educational Psychology, 46, 4-11.

Marton, F., \& Säljö, R. (1976b). On qualitative differences in learning - II: Outcome as a function of learners' conception of the task. British Journal of Educational Psychology, 46, 115-127.

Marton, F., Dall'Alba, G., \& Tse, L. (1996). Memorizing and understanding: The keys to the paradox. In D. Watkins \& J. Biggs (Eds.), The Chinese learner: Cultural, psychological, and cultural influences (pp. 69-83). Hong Kong: Comparative Education Research Centre, University of Hong Kong.

Marton, F., Wen, Q., \& Wong, K. (2005). "Read it a hundred times and the meaning will appear...": Changes in Chinese university students' views of the temporal structure of learning. Higher Education, 49, 291-318.

McKay, J., \& Kember, D. (1997). Spoon feeding leads to regurgitation: A better diet can result in more digestible learning outcomes. Higher Education Research and Development, 16(1), 55-67.

Ministry of Education. (2012). Export education levy. retrieved from http://www.educationcounts.govt.nz/statistics/international/internationalisat ion-of-education-providers-in-nz2

Morris, G. (2005). Performing pedagogy and the (re)construction of global/local selves. In M. Apple, J. Kenway \& M. Singh (Eds.), Globalising education: Policies, pedagogies and politics (pp. 135-150). New York: Peter Lang.

Ramburuth, P., \& McCormick, J. (2001). Learning diversity in higher education: A comparative study of Asian international and Australian students. Higher Education, 42, 333-335.

Rizvi, F. (2000). International education and the production of global imagination. In N. Burbules \& C. Torres (Eds.), Globalization and education: Critical perspectives (pp. 205-224). New York: Routledge. 
Robertson, M., Line, M., Jones, S., \& Thomas, S. (2000). International students, learning environments and perceptions: A case study using the Delphi technique. Higher Education Research and Development, 19(1), 89-102.

Ryan, J., \& Louie, K. (2007). False dichotomy? 'Western' and 'Confucian' concepts of scholarship and learning. Educational Philosophy and Theory, 39(4), 404-417.

Sachs, J., \& Chan, C. (2003). Dual scaling analysis of Chinese students' conceptions of learning. Educational Psychology, 23(2), 181-192.

Salili, F. (1996). Accepting personal responsibility for learning. In D. Watkins \& J. Biggs (Eds.), The Chinese learner: Cultural, psychological, and cultural influences (pp. 65-106). Hong Kong: Comparative Education Research Centre, University of Hong Kong.

Samuelowicz, K. (1987). Learning problems of overseas students: Two sides of a story. Higher Education Research and Development, 6, 121-134.

Saravanamuthu, K., \& Tinker, T. (2008). Ethics in education: The Chinese learner and post-Enron ethics. Critical Perspectives in Accounting, 19, 129-137.

Shi, L. (2006). The successors to Confucianism or a new generation? A questionnaire study on Chinese students' culture of learning English. Language, Culture and Curriculum, 19(1), 122-147.

Simpson, K., \& Tan, W. (2009). A home away from home? Chinese student evaluations of an overseas study experience. Journal of Studies in International Education, 13, 5-21.

Skyrme, G. (2007). Entering the university: The differentiated experience of two Chinese students entering a New Zealand university. Studies in Higher Education, 32(3), 357-372.

Spack, R. (1997). The rhetorical construction of multilingual students. TESOL Quarterly, 31(4), 765-744.

Spencer-Oatey, H., \& Xiong, Z. (2006). Chinese students' psychological and sociocultural adjustments to Britain: An empirical study. Language, Culture and Curriculum, 19(1), 37-53.

Tait, C. (2010) Chinese student perceptions of the effects of western university examination formats on their learning. Higher Education Quarterly, 64(3), 261-275.

Teekens, H. (2003). The requirement to develop specific skills for teaching in an intercultural setting. Journal of Studies in International Education, 7(1), 108-119.

Turner, Y. (2006). Chinese students in a UK business school: Hearing the student voice in reflective teaching and learning practice. Higher Education Quarterly, 60(1), 27-51.

Volet, S. (1999). Learning across cultures: Appropriateness of knowledge transfer. International Journal of Educational Research, 31, 625-643. 
Wang, L., \& Byram, M. (2011). 'But when you are doing your exams it is the same as in China': Chinese students adjusting to western approaches to teaching and learning. Cambridge Journal of Education, 41(4), 407-424.

Ward, C. (2001). The impact of international students on domestic students and host institutions: A literature review. Wellington: Ministry of Education.

Watkins, D. (2007). The nature of competition: The views of students from three regions of the People's Republic of China. In F. Salili \& R Hoosain (Eds.), Culture, motivation and learning: A multicultural perspective (pp. 217-233). Charlotte, NC: Information Age.

Wong, J. (2004). Are learning styles of Asian students culturally or contextually based? International Education Journal, 4(4), 154-166.

Yan, C., \& Chow, J. (2002). On the pedagogy of examinations in Hong Kong. Teaching and Teacher Education, 18(2), 139-149.

Zhang, Z., \& Brunton, M. (2007). Differences in living and learning: Chinese international students in New Zealand. Journal of Studies in International Education, 11(2), 124-140.

\section{The author}

Carolyn Tait is a Senior Lecturer in the School of Educational Psychology and Pedagogy in the Faculty of Education, Victoria University of Wellington. She researches in the area of culturally and linguistically diverse students and assessment.

Email: carolyn.tait@vuw.ac.nz 